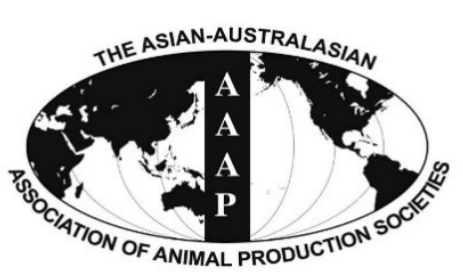

Open Access

Asian Australas. J. Anim. Sci.

Vol. 29, No. 11 : 1653-1663 November 2016

http://dx.doi.org/10.5713/ajas.16.0050

www.ajas.info

pISSN 1011-2367 elSSN 1976-5517

\title{
Proteomic Assessment of the Relevant Factors Affecting Pork Meat Quality Associated with Longissimus dorsi Muscles in Duroc Pigs
}

\author{
Jin Hyoung Cho, ${ }^{1, a}$, Ra Ham Lee ${ }^{1, a}$, Young-Joo Jeon ${ }^{1,2}$, Seon-Min Park ${ }^{3}$, Jae-Cheon Shin ${ }^{3}$, Seok-Ho Kim ${ }^{4}$, \\ Jin Young Jeong ${ }^{5}$, Hyun-sung Kang ${ }^{6}$, Nag-Jin Choi ${ }^{7}$, Kang Seok Seo ${ }^{6}$, Young Sik Cho ${ }^{8}$, MinSeok S. Kim ${ }^{9}$, \\ Sungho Ko ${ }^{10}$, Jae-Min Seo ${ }^{11}$, Seung-Youp Lee ${ }^{12}$, Jung-Hyun Shim ${ }^{13,14, *}$, and Jung-Il Chae ${ }^{1, *}$ \\ ${ }^{1}$ Department of Dental Pharmacology, School of Dentistry and Institute of Dental Bioscience, \\ BK21 plus, Chonbuk National University, Jeonju 651-756, Korea
}

\begin{abstract}
Meat quality is a complex trait influenced by many factors, including genetics, nutrition, feeding environment, animal handling, and their interactions. To elucidate relevant factors affecting pork quality associated with oxidative stress and muscle development, we analyzed protein expression in high quality longissimus dorsi muscles (HQLD) and low quality longissimus dorsi muscles (LQLD) from Duroc pigs by liquid chromatographytandem mass spectrometry (LC-MS/MS)-based proteomic analysis. Between HQLD $(n=20)$ and LQLD $(n=20)$ Duroc pigs, 24 differentially expressed proteins were identified by LC-MS/MS. A total of 10 and 14 proteins were highly expressed in HQLD and LQLD, respectively. The 24 proteins have putative functions in the following seven categories: catalytic activity (31\%), ATPase activity (19\%), oxidoreductase activity (13\%), cytoskeletal protein binding (13\%), actin binding (12\%), calcium ion binding $(6 \%)$, and structural constituent of muscle $(6 \%)$. Silver-stained image analysis revealed significant differential expression of lactate dehydrogenase A (LDHA) between HQLD and LQLD Duroc pigs. LDHA was subjected to in vitro study of myogenesis under oxidative stress conditions and LDH activity assay to verification its role in oxidative stress. No significant difference of mRNA expression level of LDHA was found between normal and oxidative stress condition. However, LDH activity was significantly higher under oxidative stress condition than at normal condition using in vitro model of myogenesis. The highly expressed LDHA was positively correlated with LQLD. Moreover, LDHA activity increased by oxidative stress was reduced by antioxidant resveratrol. This paper emphasizes the importance of differential expression patterns of proteins and their interaction for the development of meat quality traits. Our proteome data provides valuable information on important factors which might aid in the regulation of muscle development and the improvement of meat quality in longissimus dorsi muscles of Duroc pigs under oxidative stress conditions. (Key Words: Duroc, Longissimus dorsi Muscle, Liquid Chromatography-tandem Mass Spectrometry, Oxidative Stress, Meat Quality)
\end{abstract}

* Corresponding Authors: Jung-Hyun Shim. Tel: +82-61-450-2684, Fax: +82-61-450-2684, E-mail: s1004jh@gmail.com / Jung-Il Chae. Tel: +82-63-270-4024, Fax: +82-63-270-4037, E-mail: jichae@jbnu.ac.kr

${ }^{2}$ National Marine Biodiversity Institute of Korea, Seocheon 33662, Korea

${ }^{3}$ Pohang Center for Evaluation of Biomaterials, Pohang 37668, Korea.

${ }^{4}$ Aging Research Institute, Korea Research Institute of Bioscience \& BioTechnology, Daejeon 34141, Korea.

${ }^{5}$ Division of Animal Genomics and Bioinformatics, National Institute of Animal science, Rural Development Administration, Suwon, 441-706, Korea.

${ }^{6}$ Department of Animal Science and Technology, Sunchon National University, Suncheon 540-742, Korea

7 Department of Animal Science, College of Agricultural and Life Science, Chonbuk National University, Jeonju 651-756, Korea.

${ }^{8}$ Department of Pharmacy, Keimyung University, Daegu 704-701, Korea

${ }^{9}$ Department of Biomedical Engineering, Konyang University, Daejeon 35365, Korea.

${ }^{10}$ Department of Applied Bioscience, CHA University, Seongnam 463-836, Korea.

${ }^{11}$ Department of Prosthodontics, School of Dentistry and Institute of Oral Bio-Science and

Research Institute of Clinical Medicine, Chonbuk National University, Jeonju 561-756, Korea.

${ }^{12}$ Cluster for Craniofacial Development and Regeneration Research, Institute of Ora Biosciences and School of Dentistry, Chonbuk National University, Jeonju 561-756, Korea. ${ }^{13}$ Department of Pharmacy, College of Pharmacy and Natural Medicine Research Institute, Mokpo National University, Mokpo 534-729, Korea.

${ }^{14}$ The China-US (Henan) Hormel Cancer Institute, Zhengzhou, Henan 127, China.

a These authors contributed equally to this work.

Submitted Jan. 19, 2016; Revised Feb. 21, 2016; Accepted Mar. 29, 2016

\section{INTRODUCTION}

Variation in meat quality traits is a well-known problem. Meat quality traits are closely related to biological traits of live animal. Hence, biological sciences including genetics, physiology, cell biology, and biochemistry have been widely employed for decades to characterize the biological mechanisms behind major variability of meat quality traits (Bendixen, 2005). Basic knowledge of these mechanisms is essential to reduce the variation in meat quality traits such as tenderness, water-holding capacity, and color. They are also important to understand the physiology of meat animals, especially on muscle growth and development (Lametsch et al., 2002; Hwang et al., 2005). Understanding and changes related to physiochemical factors, genotypes, and many other factors influence postmortem metabolism (Monin et al., 1995; Brocks et al., 1998; Wheeler et al., 
2005). Some previous studies have indicated that meat quality is determined by postmortem muscle metabolism (Pette, 2002; Spangenburg and Booth, 2003). At slaughter, muscles become deprived of oxygen as the circulatory system shuts down. This lack of oxygen results in a shift to glycolytic (anaerobic) metabolism and a buildup of lactic acid, causing a drop in muscle pH (Frisby et al., 2005). Accelerated postmortem glycolysis reduces $\mathrm{pH}$ and increases temperature within muscle, resulting in excessive protein denaturation and inferior meat quality (Julve et al., 2000). Although extensively researched, the underlying mechanisms of many different meat quality traits are far from well understood due to many factors affecting the quality of meat (Mullen et al., 2006; Hollung et al., 2007). The proteome expressed from the genome is influenced by environmental conditions. Proteome is the molecular link between the genome and the functional quality characteristics of the meat. Therefore, proteomics is a promising and powerful tool in meat science (Lametsch and Bendixen, 2001; Morzel et al., 2004; Jia et al., 2006; Sayd et al., 2006). However proteomics has been, and still are, used in numerous studies on skeletal muscle (Picard et al., 2010).

In this study, we focus on its use in the study of livestock muscle development and meat quality with a focus on the differential expression patterns of proteins and their interactions for the development of meat quality traits.

\section{MATERIALS AND METHODS}

\section{Animals and sample collection}

The meat quality characteristics were assessed from 200 randomly selected great grandparent Duroc pigs raised from October 2011 to March 2012 for one production cycle. The live weight ranged from 100 to $120 \mathrm{~kg}$. The carcasses were kept in a freezer $\left(0^{\circ} \mathrm{C}\right)$ for $24 \mathrm{~h}$ after slaughtering. The frozen carcasses were thawed, deboned, and trimmed. The left side loin was transferred to the laboratory and placed in a deep-freezer $\left(-45^{\circ} \mathrm{C}\right)$ for analysis

\section{Gel electrophoresis and silver staining}

High quality longissimus dorsi muscles (HQLD) and low quality longissimus dorsi muscles (LQLD) tissues were collected from Duroc pigs. Total protein isolation was performed using PRO-PREP protein extraction solution (iNtRON biotechnology, Sungnam, Korea) according to the manufacturer's instructions. Concentrations of eluted proteins were measured using Pierce BCA Protein Assay Kit (Thermo scientific, Rockford, IL, USA). Equal amounts of protein samples were precipitated with cold acetone. Protein pellets dissolved in $1 \times$ sodium dodecyl sulfate (SDS) sample buffer were separated by $8 \%$ and $12 \%$ SDSpolyacrylamide gel electrophoresis (PAGE). Following
SDS-PAGE, protein spots were visualized using protocols described in PlusOne Silver staining kit (GE Healthcare Bio-Sciences, Uppsala, Sweden). The complete protocol was followed to analyze gels. To prepare gels, the protocol was modified so that glutaraldehyde was omitted from the sensitization step and formaldehyde was omitted from the silver reaction step (Yan et al., 2000). Silver-stained gels were scanned (UMAX PowerLook 2100KL Imaging system, UMAX, Taiwan) and protein profiles were compared.

\section{Liquid chromatography-tandem mass spectrometry}

The resulting tryptic peptides were separated and analyzed using reversed-phase capillary high-performance liquid chromatography directly coupled to a Thermo LTQ Orbitrap mass spectrometer using published procedure described by Zuo et al. (2001) with slight modifications. Briefly, a $0.075 \times 20 \mathrm{~mm}$ trapping column and a $0.075 \times 120$ $\mathrm{mm}$ resolving column were packed with C18AQ 218MS low formic acid $\mathrm{C} 18$ beads ( $5 \mu \mathrm{m}$ in size, $200 \AA$ pore size; C18AQ, Michrom BioResources, Auburn, CA, USA) and placed in-line. Peptides were bound to the trapping column for $10 \mathrm{~min}$ with $2 \%$ (vol/vol) aqueous acetonitrile containing $0.1 \%$ ( $\mathrm{vol} / \mathrm{vol}$ ) formic acid. The bound peptides were then eluted with a $67 \mathrm{~min}$ gradient of $2 \%$ to $90 \%$ ( $\mathrm{vol} / \mathrm{vol}$ ) acetonitrile containing $0.1 \%$ ( $\mathrm{vol} / \mathrm{vol}$ ) formic acid at a flow rate of $0.2 \mu \mathrm{L} / \mathrm{min}$. For tandem mass spectrometry, the full mass scan range mode was set at $\mathrm{m} / \mathrm{z}=50$ to 2,000 Da. After determining the charge states of the ion zoom scans, product ion spectra were acquired in MS/MS mode with relative collision energy of $55 \%$. The individual spectra from MS/MS were processed using Protein discoverer 2.1 software (Thermo scientific, USA). The generated peak list files were used to query either the MSDB or the NCBI database using the MASCOT program (http://www.matrixscience.com). We considered modifications of methionine and cysteine, peptide mass tolerance at $2 \mathrm{Da}$, $\mathrm{MS} / \mathrm{MS}$ ion mass tolerance at $0.8 \mathrm{Da}$, allowance of missed cleavage at 2 , and charge states (namely, $+1,+2$, and +3 ). Only significant hits as defined by MASCOT probability analysis were initially considered.

\section{Cell culture}

Mitotic $\mathrm{C} 2 \mathrm{C} 12$ mouse myoblasts were obtained from Chonbuk University (Jeonju, Korea). C2C12 were passaged as subconfluent monolayers in growth medium (GM) using Dulbecco's modified Eagle's medium (Invitrogen, Grand Island, NY, USA) supplemented with $20 \%$ fetal bovine serum, $200 \mathrm{mM}$ L-glutamine, 10 units/mL penicillin, and 10 $\mu \mathrm{g} / \mathrm{mL}$ streptomycin. Confluent (90\%) myoblasts were differentiated into myotubes by culturing the cells in differentiation medium (DM) with Dulbecco's modified Eagle's medium supplemented with $2 \%$ horse serum. 


\section{3-(4, 5-dimethylthiazol-2-yl)-5-(3-carboxymethoxy-} phenyl)-2-(4-sulfophenyl)-2H-tetrazolium (MTS) assay

The effects of $\mathrm{H}_{2} \mathrm{O}_{2}$ on cell viability were estimated using MTS Assay Kit (Promega, Madison, WI, USA). $\mathrm{C} 2 \mathrm{C} 12$ cells were seeded into a 96-well plate for $24 \mathrm{~h}$ and treated with $\mathrm{H}_{2} \mathrm{O}_{2}(12.5 \mu \mathrm{M}$ to $1 \mathrm{mM})$ for $24 \mathrm{~h}$ or $48 \mathrm{~h}$. MTS solution was added to the plates and incubated at $37^{\circ} \mathrm{C}$ with $5 \% \mathrm{CO}_{2}$ for $2 \mathrm{~h}$. Absorbance at $490 \mathrm{~nm}$ was recorded using a GloMax-Multi Microplate Multimode Reader (Promega, USA).

\section{Immunocytochemistry}

To detect myosin heavy chain (MYH), myogenic differentiation (MyoD), and myogenin (Myog), cells were blocked with $1 \%$ bovine serum albumin and incubated with monoclonal anti-MYH (B-5), anti-MyoD (E-1), or antiMyog (M-225) antibody at $4^{\circ} \mathrm{C}$ overnight (Santa Cruz Biotechnology, Santa Cruz, CA, USA). Probed cells were reacted with a 488-conjugated anti-mouse or 594conjugated anti-rabbit secondary antibody. For nucleus staining, cells were treated with mounting medium with 4'6-diamidino-2-phenylindole (DAPI) (Vector Laboratories, Inc. Burlingame, CA, USA). The cells were visualized using a FluoView confocal laser microscope (Fluoview FV10i, Olympus Corporation, Tokyo, Japan).

Reverse transcription polymerase chain reaction and real-time polymerase chain reaction analysis

Total RNA isolation was performed using TRIzol reagent (Invitrogen, USA) according to the manufacturer's instructions. Briefly, total RNA levels were quantified by absorbance at $260 \mathrm{~nm}$. RNA integrity was evaluated by $1.2 \%$ (w/v) agarose gel. Total RNA ( $2 \mu \mathrm{g}$ amounts) was reversetranscribed into cDNA using QuantiTect Reverse Transcription Kit (Qiagen, Chatsworth, CA, USA) according to the manufacturer's instructions. Real-time polymerase chain reaction analysis (PCR) was performed with SYBR green Premix Ex Taq II (Takara, Dalian, China) using Applied Biosystems StepOne Plus Real-time PCR System (Applied Biosystems, Carlsbad, CA, USA). Relative quantification analysis was performed using the comparative $\mathrm{Ct}\left(2^{(-\Delta \Delta C \mathrm{CT})}\right)$ method. The expression of glyceraldehyde-3-phosphate dehydrogenase (GAPDH) and $\beta$-actin was used as endogenous control for the detection of mRNA expression levels. Primers used in the study were listed in Table 4.

\section{Kinetic determination of LDH activity}

Commercially available kits for lactate dehydrogenase (DLDH-100, QuantiChrom Lactate Dehydrogenase Kit, Gentaur Molecular, Hayward, CA, USA) were used according to the manufacturers' instructions (Stentz et al., 2010).

\section{RESULTS AND DISCUSSION}

\section{Animals and phenotypes}

The average weight before and after slaughtering of the GGP pigs were $98.23 \mathrm{~kg}$ and $89.98 \mathrm{~kg}$, respectively. Difference of $10 \mathrm{~kg}$ before and after slaughtering was recorded. Important economic traits such as lean percent and eye muscle area showed an average value of $54.74 \%$ and $26.03 \mathrm{~cm}^{2}$, respectively (Table 1 ).

\section{Protein profiles in HQLD and LQLD from Duroc pigs}

Meat qualities were evaluated by Korea Institute for Animal Products Quality Evaluation (KAPE) authorized by South Korean government to perform animal products grading service. The normality test was applied to show normal distribution of the traits. The highest and lowest meat grades for $\mathrm{pH}$ and water holding capacity were identified from the sample which accounted for $10 \%$ (20 heads) of the total population (Table 2). To obtain a comprehensive overview of protein components in HQLD and LQLD from 12 individuals, protein profiles of whole lysate of HQLD and LQLD separated by $8 \%$ and $12 \%$ SDSPAGE were assessed by silver-stained image analysis (Figure 1A). Patterns of total protein components in whole lysate of HQLD and LQLD were similar among the individual six groups. However, significantly fewer proteins (i.e. band $\mathrm{a}$ and $\mathrm{b}$ ) were expressed in HQLD compared to in LQLD. Two different protein spots were identified by a mass spectrometric analysis. Myosin binding protein $\mathrm{C}$ (MYBPC2) expressed during skeletal muscle development (Gurnett et al., 2010) had higher expression in HQLD than in LQLD. However, lactate dehydrogenase A (LDHA) catalyzing the conversion of pyruvate to lactate during glycolysis (Fan et al., 2011) had higher expression in LQLD than in HQLD (Figure 1B).

\section{Protein identification and gene ontological classification by LC-MS/MS-based proteomic analysis}

Next, we performed liquid chromatography-tandem mass spectrometry (LC-MS/MS)-based proteomic analysis to elucidate the proteins involved in longissimus dorsi muscle (i.e. HQLD and LQLD) properties involved in meat quality. Among the total 24 proteins identified, 10 and 14 proteins were confirmed to be highly expressed in HQLD and LQLD, respectively. All identified proteins were clustered into the following seven categories (Figure 2A) based on information obtained from DAVID gene ontology (GO) database (http://david.abcc.ncifcrf.gov) and UniProt (http://www.uniprot.org): Catalytic activity (31\%), ATPase activity (19\%), oxidoreductase activity (13\%), cytoskeletal protein binding $(13 \%)$, actin binding $(12 \%)$, calcium ion binding $(6 \%)$ and structural constituent of muscle $(6 \%)$ (Supplementary Table S1). The GO analysis was performed 
Table 1. Phenotypic record of meat quality traits in Duroc pigs

\begin{tabular}{|c|c|c|c|c|c|c|}
\hline Traits & $\mathrm{N}$ & Mean & Min & Max & Median & Std \\
\hline Eye muscle area $\left(\mathrm{cm}^{2}\right)$ & 199 & 28.13 & 20.99 & 33.00 & 28.15 & 0.218 \\
\hline Age at $90 \mathrm{~kg}(\mathrm{~d})$ & 199 & 142.97 & 123 & 171 & 142 & 0.960 \\
\hline Average daily gain (g) & 199 & 643.34 & 493.30 & 780.00 & 641.75 & 5.806 \\
\hline Backfat thickness (mm) & 199 & 14.78 & 10.26 & 24.23 & 14.48 & 0.184 \\
\hline Loin depth (mm) & 199 & 55.61 & 50.40 & 60.40 & 55.80 & 0.189 \\
\hline Weight at end of test day $(\mathrm{kg})$ & 199 & 99.18 & 75.00 & 120.00 & 100.00 & 0.861 \\
\hline \multicolumn{7}{|l|}{ Meat quality characteristics } \\
\hline $\mathrm{pH} 24 \mathrm{~h}$ & 199 & 5.71 & 5.43 & 6.03 & 5.71 & 0.109 \\
\hline Brightness & 199 & 54.50 & 46.71 & 62.25 & 54.40 & 2.981 \\
\hline Redness & 199 & 16.98 & 9.75 & 21.10 & 17.27 & 1.984 \\
\hline Yellowness & 199 & 11.31 & 5.45 & 16.29 & 11.52 & 2.076 \\
\hline Water holding capacity & 199 & 73.55 & 56.99 & 89.04 & 72.80 & 6.874 \\
\hline Cooking loss & 199 & 14.53 & 6.65 & 22.95 & 14.64 & 2.998 \\
\hline Moisture & 199 & 72.76 & 63.67 & 79.33 & 73.00 & 1.922 \\
\hline Color, sensory test & 199 & 5.37 & 2.50 & 7.50 & 5.42 & 0.873 \\
\hline Flavor, sensory test & 199 & 5.28 & 1.25 & 8.00 & 5.33 & 1.187 \\
\hline Tenderness, sensory test & 199 & 5.28 & 1.25 & 8.50 & 5.33 & 1.450 \\
\hline Juiciness, sensory test & 199 & 5.10 & 1.25 & 9.75 & 5.25 & 1.506 \\
\hline Palatability, sensory test & 199 & 5.13 & 1.25 & 8.50 & 5.25 & 1.491 \\
\hline Shear force & 199 & 6.24 & 2.46 & 12.94 & 5.63 & 2.215 \\
\hline \multicolumn{7}{|l|}{ Biochemical measures } \\
\hline Palmitic acid & 199 & 25.58 & 22.74 & 28.08 & 25.68 & 1.044 \\
\hline Oleic acid & 199 & 35.89 & 10.89 & 44.91 & 40.00 & 10.118 \\
\hline Stearic acid & 199 & 17.19 & 9.72 & 43.71 & 13.17 & 9.799 \\
\hline Linolenic acid & 199 & 8.42 & 5.31 & 13.06 & 8.06 & 1.743 \\
\hline
\end{tabular}

using DAVID Bioinformatics Resources 6.7 categories for both molecular function (MF) and biological process (BP). Depending on the MF in which the proteins were involved, they were categorized into the following three groups (Figure 2B): Cytoskeletal protein binding (40\%), actin binding (40\%), and structural constituent of muscle (20\%) (Supplementary Table S2). Depending on the BP in which the proteins were involved, they were categorized into the following five groups (Figure 2C): Primary metabolic process $(26 \%)$, cellular metabolic process $(26 \%)$, catabolic process $(18 \%)$, nitrogen compound metabolic process
(19\%), and oxidation reduction (11\%) (Supplementary Table S3). The expression changes of the up- and downregulated proteins in HQLD and LQLD of Duroc pigs were summarized in Table 3. LDHA was selected and subjected to further analysis by LDH activity assay and in vitro study of myogenesis under oxidative stress conditions.

\section{Gross changes in $\mathrm{C2C12}$ myoblasts in response to myogenic differentiation}

C2C12 myoblasts serve as an experimentally tractable model system for investigating the molecular basis of

Table 2. High- or low-meat quality traits of longissimus dorsi muscles in Duroc pigs

\begin{tabular}{|c|c|c|c|c|c|c|}
\hline Traits & $\overline{\mathrm{N}}$ & Mean & Min & Max & Median & Std \\
\hline \multicolumn{7}{|c|}{ High quality of longissimus dorsi muscles } \\
\hline $\mathrm{pH} 24 \mathrm{~h}$ & 20 & 5.82 & 5.73 & 6.03 & 5.80 & 0.083 \\
\hline Water holding capacity & 20 & 73.96 & 65.60 & 85.75 & 73.42 & 5.699 \\
\hline Cooking loss & 20 & 14.40 & 7.30 & 21.45 & 13.82 & 3.457 \\
\hline Moisture & 20 & 72.95 & 70.17 & 75.33 & 72.67 & 1.369 \\
\hline Shear force & 20 & 6.44 & 3.83 & 10.55 & 6.02 & 2.229 \\
\hline \multicolumn{7}{|c|}{ Low quality of longissimus dorsi muscles } \\
\hline $\mathrm{pH} 24 \mathrm{~h}$ & 20 & 5.60 & 5.55 & 5.64 & 5.60 & 0.031 \\
\hline Water holding capacity & 20 & 73.76 & 62.33 & 87.35 & 72.60 & 7.135 \\
\hline Cooking loss & 20 & 15.39 & 9.27 & 22.95 & 15.41 & 2.850 \\
\hline Moisture & 20 & 72.74 & 68.00 & 75.00 & 73.00 & 1.713 \\
\hline Shear force & 20 & 6.14 & 2.46 & 10.29 & 5.60 & 2.036 \\
\hline
\end{tabular}


A

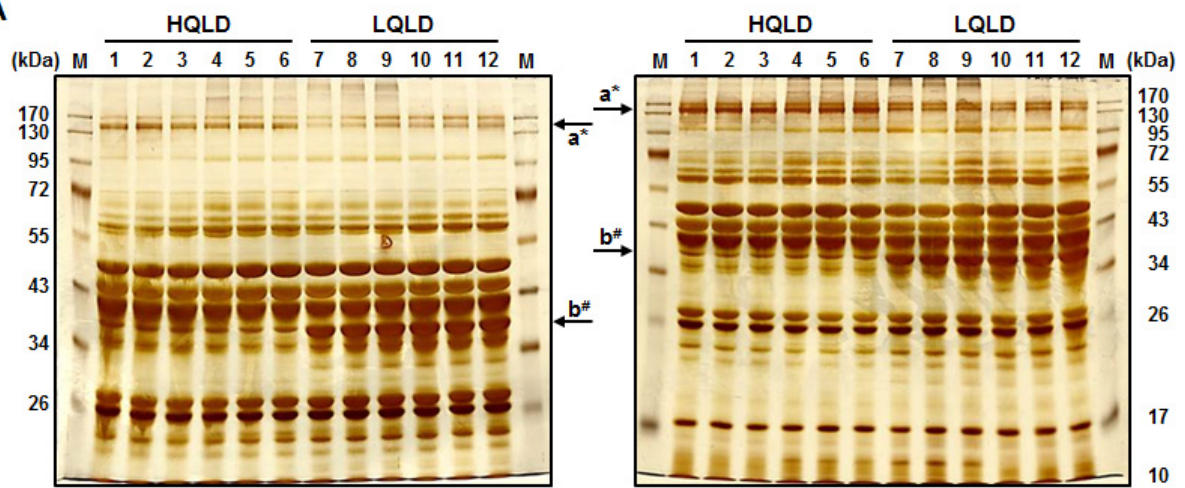

B

\begin{tabular}{|c|l|l|l|l|c|c|}
\hline Band & Accession no. & UniGene ID & Gene name & Protein name & MW (kDa) & Score \\
\hline $\mathrm{a}^{\star}$ & F1RH20 & Ssc. 83876 & MYBPC2 & Myosin binding protein C & 127.6 & 120.82 \\
\hline $\mathrm{b}^{\boldsymbol{\#}}$ & P00339 & Ssc. 50275 & LDHA & Lactate dehydrogenase A & 36.6 & 58.91 \\
\hline
\end{tabular}

Figure 1. Protein profiles of high quality longissimus dorsi muscles (HQLD) and low quality longissimus dorsi muscles (LQLD) from Duroc pigs by image analysis. (A) The overall patterns of total protein bands from individuals. All gels were visualized by sliver staining. (B) Two different protein spots were identified by a mass spectrometric analysis. $a^{*}$ : MYBPC2, myosin binding protein C; $b^{\#}$ : LDHA, lactate dehydrogenase A.

skeletal muscle cell specification and development (Kislinger et al., 2005). A temporally well-defined myogenic differentiation program can be selectively triggered in cultured $\mathrm{C} 2 \mathrm{C} 12$ myoblasts upon withdrawal of GM and mitogens (Gramolini and Jasmin, 1999). When switched to DM, mitotic $\mathrm{C} 2 \mathrm{C} 12$ myoblasts rapidly cease proliferation and initiate a synchronously terminal differentiation program (Figure 3A). To investigate the patterns of protein expression and efficiency of myotube formation during myogenesis under oxidative stress condition, undifferentiation $\mathrm{C} 2 \mathrm{C} 12$ cells were treated with various concentrations of $\mathrm{H}_{2} \mathrm{O}_{2}(12.5 \mu \mathrm{M}$ to $1 \mathrm{mM})$. Cytotoxicity was negligible with $200 \mu \mathrm{M} \mathrm{H}_{2} \mathrm{O}_{2}$. However, up to $1 \mathrm{mM} \mathrm{H}_{2} \mathrm{O}_{2}$ did reduce viability which was confirmed by 3-(4, 5-dimethylthiazol-2-yl)-5-(3-carboxymethoxyphenyl) -2-(4-sulfophenyl)-2H-tetrazolium) (MTS) assay (Figure 3B). Control cells exhibited striking morphological changes over the course of 3 to 7 days, eventually fusing into mature multinucleated myotubes (i.e. by day 5). However, $\mathrm{H}_{2} \mathrm{O}_{2}$ treated cells exhibited thread-like shape without fusing into

A

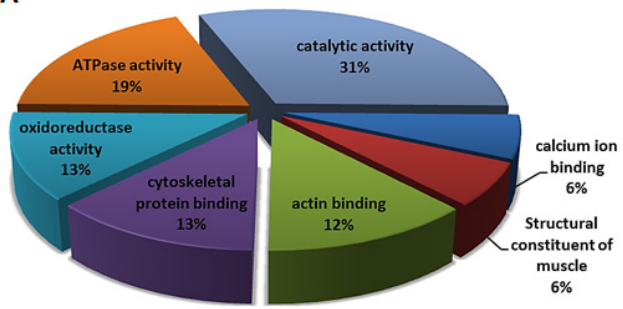

B

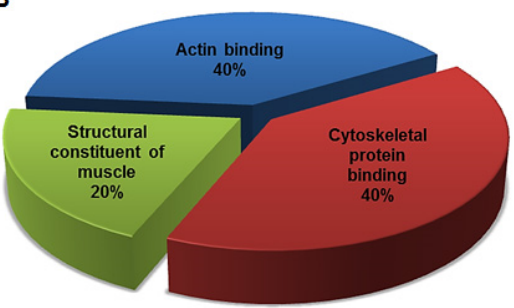

C

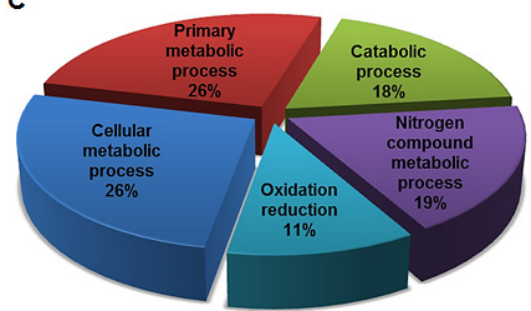

Figure 2. Ontological classifications of differentially regulated proteins in high quality longissimus dorsi muscles (HQLD) and low quality longissimus dorsi muscles (LQLD) from Duroc pigs. Of the total 24 identified proteins, 10 and 14 proteins were highly expressed in HQLD and LQLD, respectively. (A) The identified proteins were clustered into 7 categories based on information obtained from DAVID gene ontology (GO) database; (B) The identified proteins were clustered into 3 categories based on their molecular function; (C) The identified proteins were clustered into 5 categories based on their biological processes. 
Table 3. List of differentially expressed genes on high- and low quality of longissimus dorsi muscles in duroc pigs

\begin{tabular}{|c|c|c|c|c|c|c|c|c|c|}
\hline \multirow[t]{2}{*}{ No } & \multirow[t]{2}{*}{ UniProt $^{1}$} & \multirow[t]{2}{*}{ UniGene $^{2}$} & \multirow[t]{2}{*}{ Protein identified } & \multirow[t]{2}{*}{ Gene name } & \multirow[t]{2}{*}{$\mathrm{pI}$} & \multirow{2}{*}{$\begin{array}{l}\text { MW } \\
(\mathrm{kDa})\end{array}$} & \multirow{2}{*}{$\begin{array}{l}\text { Seq. } \\
\text { Cov } \\
(\%)\end{array}$} & \multicolumn{2}{|c|}{$\begin{array}{l}\text { Individual } \\
\text { ion score }\end{array}$} \\
\hline & & & & & & & & HQLD & LQLD \\
\hline \multicolumn{10}{|c|}{ Highly expressed genes in HQLD } \\
\hline 1 & Q5S1S4 & Ssc. 10960 & Carbonic anhydrase 3 & $C A 3$ & 7.85 & 29.4 & 53.46 & 150.33 & 82.96 \\
\hline 2 & F1RKI3 & Ssc: 100518898 & histidine triad nucleotide-binding protein 1 & LOC100518898 & 6.87 & 13.7 & 11.11 & 3.48 & 0 \\
\hline 3 & Q9TSX9 & Ssc. 2979 & Peroxiredoxin- 6 & PRDX6 & 6.01 & 25 & 7.59 & 2.67 & 0 \\
\hline 4 & D3GGC9 & Ssc. 3835 & Actinin-associated LIM protein 3 & PDLIM3 & 8.12 & 30.5 & 5.42 & 5.96 & 2.24 \\
\hline 5 & F1RGK5 & Ssc. 51787 & Tropomyosin alpha-3 chain & TPM3 & 4.75 & 28.9 & 5.24 & 7.13 & 0 \\
\hline 6 & P34930 & Ssc. 5145 & Heat shock $70 \mathrm{kDa}$ protein $1 \mathrm{~A}$ & $H S P A 1 A$ & 5.73 & 70 & 3.12 & 12.17 & 4.39 \\
\hline 7 & Q04967 & Ssc.114 & Heat shock $70 \mathrm{kDa}$ protein 6 & HSPA6 & 6.06 & 71.1 & 2.95 & 9.69 & 3.98 \\
\hline 8 & F1SEN8 & Ssc. 97236 & LIM domain-binding protein 3 & $L D B 3$ & 7.78 & 75.8 & 1.68 & 2.83 & 2.13 \\
\hline 9 & F1RH20 & Ssc. 83876 & Myosin-binding protein $\mathrm{C}$, fast-type & $M Y B P C 2$ & 6.55 & 127.6 & 1.58 & 2.57 & 0 \\
\hline 10 & F1SMN5 & Ssc. 46794 & Filamin-C & $F L N C$ & 5.96 & 290.2 & 0.44 & 4.59 & 0 \\
\hline \multicolumn{10}{|c|}{ Highly expressed genes in LQLD } \\
\hline 11 & $\mathrm{P} 00355$ & Ssc. 16135 & Glyceraldehyde-3-phosphate dehydrogenase & GAPDH & 8.35 & 35.8 & 46.85 & 81.05 & 447.46 \\
\hline 12 & P00339 & Ssc. 50275 & L-lactate dehydrogenase A & LDHA & 8.07 & 36.6 & 39.76 & 129.85 & 230.24 \\
\hline 13 & F1SKJ8 & Ssc. 26154 & Parvalbumin 1 & PVALB1 & 5.07 & 12.1 & 20.91 & 15.89 & 22.65 \\
\hline 14 & F1SLA0 & Ssc. 279 & ATP synthase subunit beta & $A T P 5 B$ & 5.27 & 56.3 & 8.71 & 0 & 4.89 \\
\hline 15 & Q9GJT2 & Ssc. 217 & S-formylglutathione hydrolase & $E S D$ & 7.02 & 31.5 & 7.45 & 0 & 2.32 \\
\hline 16 & F1RFH9 & Ssc. 55270 & Sarcoplasmic/endoplasmic reticulum calcium ATPase 1 & $A T P 2 A 1$ & 5.29 & 109.1 & 6.45 & 1.96 & 21.11 \\
\hline 17 & Q06AA5 & Ssc. 26272 & Tetraspanin-9 & TSPAN9 & 7.44 & 26.8 & 6.28 & 0 & 2.32 \\
\hline 18 & F1S6Q7 & Ssc: 100523423 & ATP synthase subunit delta, mitochondrial -like & LOC100523423 & 5.25 & 17.5 & 5.36 & 0 & 4.15 \\
\hline 19 & A1X898 & Ssc.97027 & Procollagen-proline 2-oxoglutarate-4-dioxygenase & P4HA1 & 6.01 & 60.9 & 4.49 & 0 & 2.47 \\
\hline 20 & F1RFU5 & Ssc. 3588 & Aspartate aminotransferase & GOT2 & 8.73 & 24.1 & 3.72 & 0 & 4.7 \\
\hline 21 & E7EBY5 & Ssc. 26469 & MACRO domain containing protein 1 & MACRODI & 9.22 & 35.1 & 3.69 & 2.39 & 4.3 \\
\hline 22 & Q2XQV4 & Ssc. 11147 & Aldehyde dehydrogenase, mitochondrial & $A L D H 2$ & 6.87 & 56.9 & 3.26 & 3.59 & 4.95 \\
\hline 23 & I3LL15 & Ssc. 16302 & Uricase & $U O X$ & 8.32 & 34.9 & 2.63 & 1.78 & 4.37 \\
\hline 24 & F1SLR6 & Ssc. 5041 & Putative ribosomal RNA methyltransferase NOP2 & NOP2 & 9.06 & 90.2 & 1.95 & 0 & 6.07 \\
\hline
\end{tabular}

pI, isoelectric point of the protein; MW, molecular weight of the protein; Seq. Cov, percentage of sequence coverage; HQLD, high quality of longissimus dorsi muscles; LQLD, low quality of longissimus dorsi muscles.

${ }^{1}$ UniProt, Accession number in the UniProt database.

${ }^{2}$ UniGene, UniGene number from NCBI (National Center for Biotechnology Information) database.

${ }^{3}$ Individual ion score, TurboSEQUEST or gMASCOT score.

mature multinucleated myotubes (Figure 3C). Myotubes were identified by immunocytochemistry with anti-myosin heavy chain (MYH) antibody (Figure 3D).

\section{In vitro model of myogenesis under oxidative stress condition}

The expression of myogenic regulatory factors consisting of MyoD and Myog characterizes various phases of skeletal muscle development, including myoblast proliferation, cell-cycle exit, cell fusion, and the maturation of myotubes to form myofibers (Lee et al., 2014). MyoD, the chief regulatory molecule of myogenic differentiation (Langen et al., 2004), plays an important role in cell cycle exit of differentiating myoblasts (Guo et al., 1995; Halevy et al., 1995) Terminal differentiation of myoblast, driven by expression of Myog, is essential for the formation of functional multinucleated myofibers (Liu et al., 2012). In order to study the patterns of MyoD and Myog expression (gene and protein levels) depending on oxidative stress condition during myogenesis, we used western blot and RTPCR analyses. Our data revealed that, among various genes subjected to comparison, MyoD had significant $(\mathrm{p}<0.0001)$ higher expression under oxidative stress condition than under normal condition on day 3. The expression of MyoD on day 3 was not significantly different from that on day 2 under oxidative stress condition. Myog had significant $(p<0.0001)$ higher expression under normal condition than under oxidative stress condition at day 6 . Under oxidative stress condition, the expression of Myog was significantly $(p<0.05)$ decreased at day 6 compared to that at day 5 (Figure 3E). The mRNA expression levels for selected genes were analyzed by quantitative real-time PCR with specific primer (Table 4). Western blot analysis data revealed that, of different proteins subjected to comparison, MyoD had significantly $(\mathrm{p}<0.0001)$ higher expression under oxidative stress condition than under normal condition at day 2. Under oxidative stress condition, the expression of MyoD at $12 \mathrm{~h}$ was not significantly different from that at 6 h. Moreover, Myog had significantly $(\mathrm{p}<0.0001)$ higher expression under normal condition than under oxidative stress condition at day 4. Under oxidative stress condition, the expression of Myog was significantly more decreased ( $\mathrm{p}$ $=0.0016$ ) at day 4 than at day 3 (Figure 3F). These results indicate that $\mathrm{H}_{2} \mathrm{O}_{2}$-induced oxidative stress inhibits 


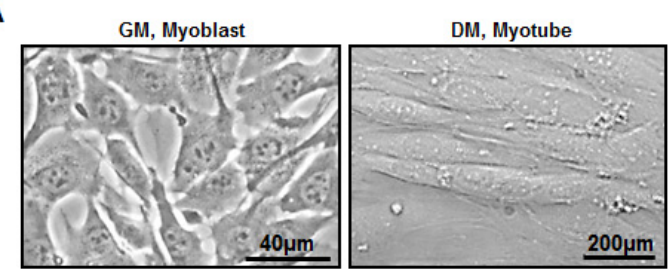

C
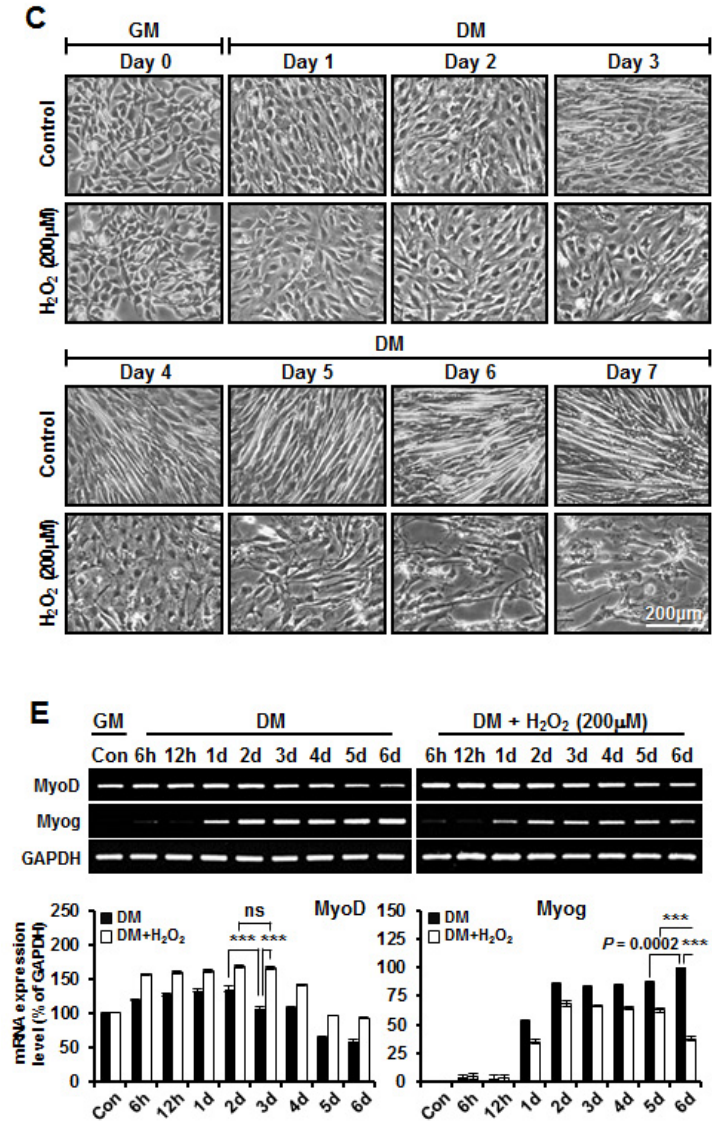

B

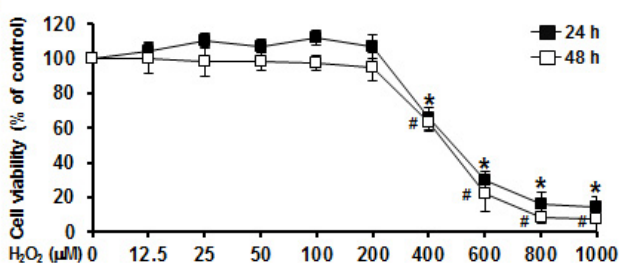

D

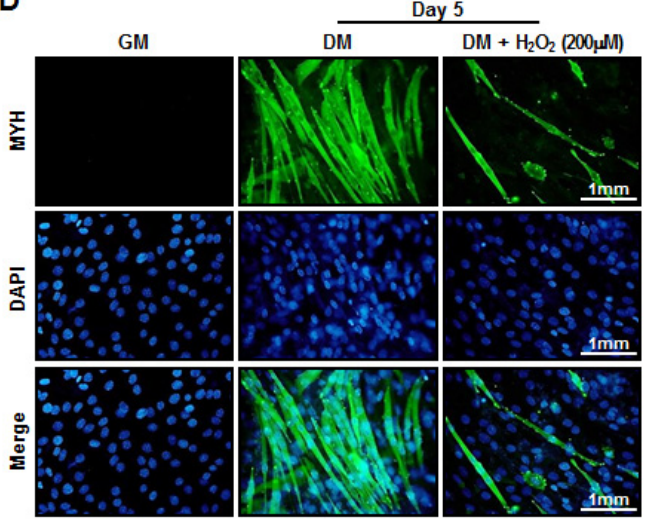

Figure 3. Gross changes and cell viability in myogenic differentiation under oxidative stress condition. (A) Morphological changes of myoblast during myogenesis. Arrow head and dashed lines indicating myoblast with mono nucleus and myotube with three or more nuclei, respectively; (B) Cytotoxic effects of $\mathrm{H}_{2} \mathrm{O}_{2}$ in $\mathrm{C} 2 \mathrm{C} 12$ treated with the various concentrations of $\mathrm{H}_{2} \mathrm{O}_{2}(12.5 \mu \mathrm{M}$ to $1 \mathrm{mM})$. Data represented mean value of three independent experiments; bars, standard deviation. * Significantly different compared to untreated conditions (24 h); \#, significantly different compared to untreated conditions (48 h) ( $=3$, p $<0.0001)$; (C) Light microscopy-based images of undifferentiated (day 0) proliferating $\mathrm{C} 2 \mathrm{C} 12$ myoblasts and differentiating cells at various time points (up to day 7 ) under normal and oxidative stress conditions $\left(\mathrm{H}_{2} \mathrm{O}_{2}[200 \mu \mathrm{M}]\right.$ ); (D) Immunocytochemistry presented the $\mathrm{MYH}$ expression levels of undifferentiated (day 0) and differentiated (day 5). GM, growth medium; DM, differentiation medium. (E) Oxidative stress induced down-regulation of Myog gene expression and continuous up-regulation of MyoD gene expression with glyceraldehyde-3-phosphate dehydrogenase (GAPDH) as a control; (F) Oxidative stress induced down-regulation of Myog protein expression and continuous upregulation of MyoD protein expression with $\beta$-actin as a control. Student's t test was performed to evaluate statistical significance (ns, non-significant; $* * * \mathrm{p}<0.0001 ;$ mean \pm standard error of the mean; $\mathrm{n}=3$ ).

myogenesis through the down-regulation of Myog and the continuous up-regulation of MyoD.

\section{Relationships between $L D H A$ gene expression and myogenesis}

Previous studies reported that porcine myogenic differentiation $1(M y o D 1)$ gene has been mapped to swine chromosome 2p14-p17 which is involved in the regulation of the proliferation and differentiation of skeletal muscle cells. $L D H A$ genes mapped close to MyoD are involved in energy metabolism and protein transport processes. $L D H A$ genes might play important roles in muscle development (Qiu et al., 2010). However, little is known about porcine $L D H A$ genes. Therefore, we determined the relationships 
Table 4. Primer sequences used to generate templates for reverse transcription polymerase chain reaction

\begin{tabular}{lcclc}
\hline Gene name & Symbol & GenBank ID & Primer sequence $\left(5^{\prime} \rightarrow 3\right.$ ') & Size $(\mathrm{bp})$ \\
\hline Myogenic differentiation & MyoD & NM_010866 & F: GAT GGC ATG ATG GAT TAC AGC & 528 \\
& & & R: GAC TAT GTC CTT TCT TTG GGG & 424 \\
Myogenin & Myog & NM_031189 & F: GCT CAG CTC CCT CAA CCA G & R: ATG TGA ATG GGG AGT GGG GA \\
Glyceraldehyde-3-phosphate dehydrogenase & GAPDH & NM_008084 & F: ACC ACA GTC CAT GCC ATC AC & 452 \\
& & & R: TAC AGC AAC AGG GTG GTG GA & \\
\hline
\end{tabular}

between LDHA gene expression and myogenesis under normal and oxidative stress condition. To investigate whether oxidative stress regulated LDHA expression at genetic levels, we used quantitative real-time PCR. The mRNA expression levels of selected genes were subjected to quantitative real-time PCR with specific primers (Table 4). Figure $4 \mathrm{~A}$ showed that $L D H A$ genes were increased up to day 5 during myogenesis under normal and oxidative stress condition. LDHA expression was significantly $(\mathrm{p}=$ 0.0088 ) higher under oxidative stress condition. These results indicate that up-regulated $L D H A$ genes induced by oxidative stress might play dysfunctional roles in myogenesis.

\section{Antioxidant properties of resveratrol}

Resveratrol (RSV), a well-known phytocompound and
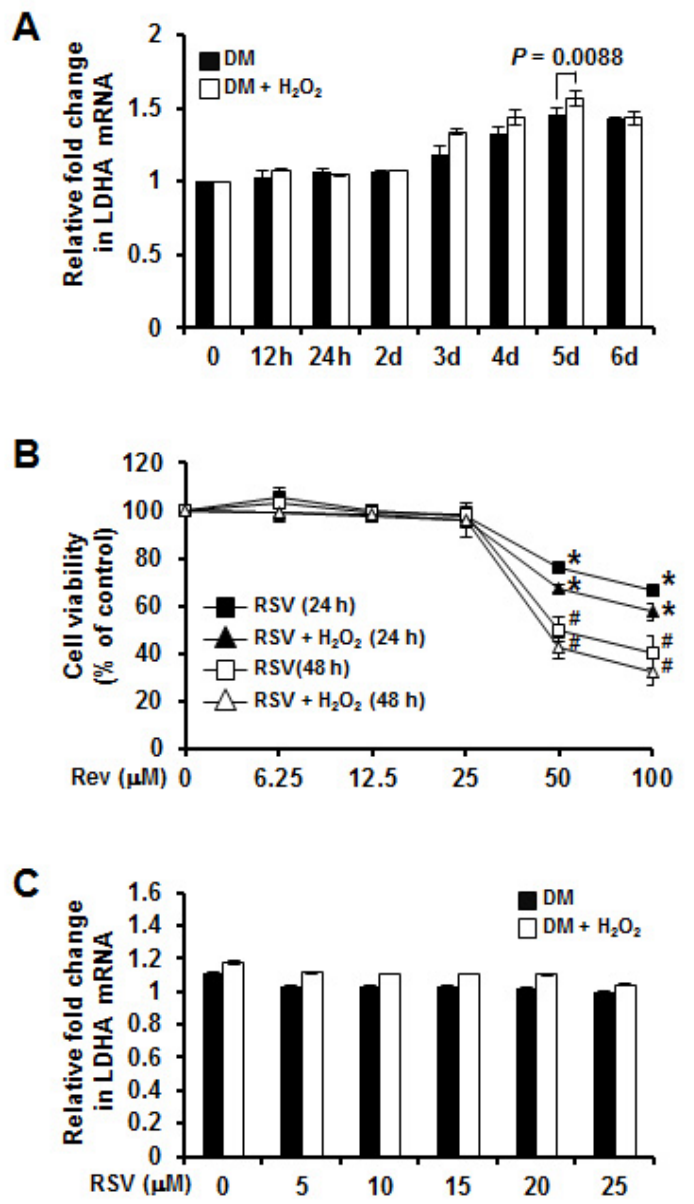

Figure 4. Gene and protein expression levels on high quality longissimus dorsi muscles (HQLD) and low quality longissimus dorsi muscles (LQLD) depending on oxidative stress. Myoblast and myotube cDNA and protein were determined by real-time PCR analysis and western blot analysis, respectively. (A) The quantitative differences of lactate dehydrogenase A (LDHA) at the transcriptional level were measured by real-time PCR during myogenesis with $\beta$-actin as control; (B) Cytotoxic effects of resveratrol (RSV) in C2C12 treated with various concentrations of RSV $(6.25 \mu \mathrm{M}$ to $100 \mu \mathrm{M})$. Data represented mean value of three independent experiments; bars, standard deviation. * Significantly different compared with untreated conditions $(24 \mathrm{~h})$; \#, significantly different compared to untreated conditions (48 h) ( $\mathrm{n}=3, \mathrm{p}<0.0001)$; (C) Quantitative differences of LDHA at the transcriptional level were measured by real-time PCR in RSVtreated $\mathrm{C} 2 \mathrm{C} 12$ during myogenesis. 
food component, has antioxidative and multifunctional bioactivities ( $\mathrm{Wu}$ et al., 2013). Previous studies have reported that RSV in skeletal muscle acts on protein catabolism and muscle function and confers resistance against oxidative stress, injury, and cell death. However, its action mechanisms and protein targets in myogenesis process are not completely understood (Montesano et al., 2013). Therefore, we determined the effect of RSV on LDHA gene expression in myogenesis under oxidative stress condition. $\mathrm{C} 2 \mathrm{C} 12$ cells were treated with various concentrations of RSV $(6.25 \mu \mathrm{M}$ to $100 \mu \mathrm{M})$. Cytotoxicity was negligible with RSV $(25 \mu \mathrm{M})$ under normal and oxidative stress conditions. However, up to $100 \mu \mathrm{M}$ RSV did reduce viability which was confirmed by MTS assay (Figure 4B). However, after RSV treatment, there was no significant difference in mRNA expression of LDHA between normal condition and oxidative stress condition (Figure 4C).

\section{Confirmation of lactate dehydrogenase activity}

Elevation of plasmatic LDH levels are characteristic responses to strenuous exercise which are often used as indicators of muscle damage (Kanter et al., 1988; Bouzid et al., 2014). However, difference of LDH activity between HQLD and LQLD of Duroc pigs is not well determined. Our data showed that LDH activity was significantly $(\mathrm{p}=$ 0.0003 ) higher in LQLD than in HQLD of Duroc pigs (Figure 5A). Moreover, higher LDH activity was positively correlated with in vitro model of myogenesis under oxidative stress condition. In addition, LDH activity was significantly reduced by RSV treatment (Figure 5B). We also confirmed the patterns of MyoD and Myog expression under oxidative stress condition and RSV treatment during myogenesis by immunocytochemistry. Oxidative stress induced down-regulation of Myog and continuous upregulation of MyoD. The down-regulation induced by oxidative stress was recovered by RSV treatment. The upregulation of MyoD induced by the oxidative stress was reduced by the treatment of RSV in myogenesis (Figure 5C). In addition, there was a significant correlation between MyoD and Myog expression (gene and protein levels) under oxidative stress condition during myogenesis (Figure 5D). These results indicate that high activity of LDH by oxidative stress will result in dysfunction of myogenesis and that RSV treatment will result in its functional recovery.

In conclusion, our data demonstrated that up- or down-
A

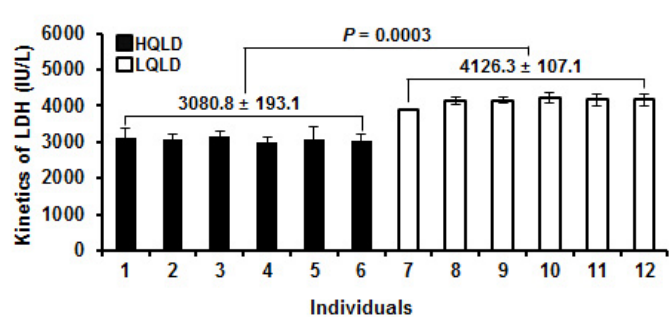

B

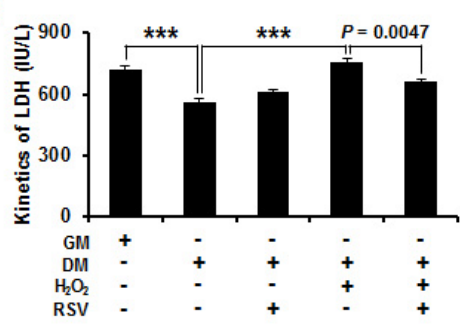

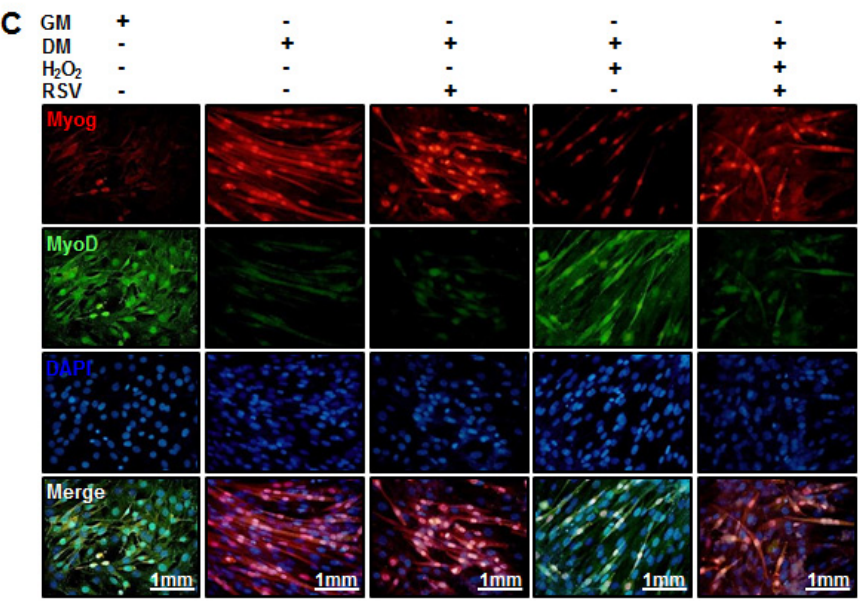

D $+-\quad-\quad-$ GM

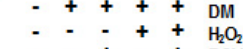

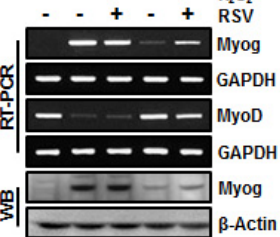

Figure 5. Antioxidant effect of resveratrol in lactate dehydrogenase activity and myogenesis. (A) Difference of lactate dehydrogenase (LDH) activity between high quality longissimus dorsi muscles (HQLD) and low quality longissimus dorsi muscles (LQLD) from individual six groups of Duroc pigs. (B) In vitro model of myogenesis under oxidative stress condition and changes of lactate dehydrogenase activity by resveratrol (RSV) treatment. Student's $t$ test was performed to evaluate statistical significance $(* * * p<0.0001$; mean \pm standard error of the mean; $n=3$ ); (C) Patterns of myogenic differentiation (MyoD) and myogenin (Myog) expression depending on oxidative stress condition and RSV treatment during myogenesis by immunocytochemistry; (D) Patterns of MyoD and Myog expression (gene and protein levels) depending on oxidative stress condition and RSV treatment during myogenesis by reverse transcription polymerase chain reaction and western blot analysis. 
regulation of genes and proteins are involved in muscle development, muscle function, actin organization, oxidative stress, cell proliferation, cell differentiation, and cell growth. In this paper, differential expression patterns of genes and their interaction are found to be important for the development of meat quality traits. Our proteome data provided valuable information on differentially expressed genes $(L D H A)$ and activity of LDH in HQLD and LQLD from Duroc pigs, which may aid in the regulation of muscle development. Our study provided experimental evidence for $\mathrm{RSV}$ as an important regulator to improve meat quality grades in porcine. However, further study is required to determine the relationship between differential expression of genes or proteins and their direct effects on meat quality.

\section{CONFLICT OF INTEREST}

We certify that there is no conflict of interest with any financial organization regarding the material discussed in the manuscript.

\section{ACKNOWLEDGMENTS}

This work was carried out with the support of "Cooperative Research Program for Agriculture Science \& Technology Development (Project No. PJ011682)" Rural Development Administration, Republic of Korea.

\section{REFERENCES}

Bendixen, E. 2005. The use of proteomics in meat science. Meat Sci. 71:138-149.

Bouzid, M. A., O. Hammouda, R. Matran, S. Robin, and C. Fabre. 2014. Changes in oxidative stress markers and biological markers of muscle injury with aging at rest and in response to an exhaustive exercise. PLoS One 9:e90420.

Brocks, L., B. Hulsegge, and G. Merkus. 1998. Histochemical characteristics in relation to meat quality properties in the Longissimus Lumborum of fast and lean growing lines of Large White pigs. Meat Sci. 50:411-420.

Fan, J., T. Hitosugi, T. W. Chung, J. Xie, Q. Ge, T. L. Gu, R. D. Polakiewicz, G. Z. Chen, T. J. Boggon, S. Lonial, F. R. Khuri, S. Kang, and J. Chen. 2011. Tyrosine phosphorylation of lactate dehydrogenase $\mathrm{A}$ is important for $\mathrm{NADH} / \mathrm{NAD}(+)$ redox homeostasis in cancer cells. Mol. Cell. Biol. 31:49384950.

Frisby, J., D. Raftery, J. P. Kerry, and D. Diamond. 2005. Development of an autonomous, wireless $\mathrm{pH}$ and temperature sensing system for monitoring pig meat quality. Meat Sci. 70:329-336.

Gramolini, A. O. and B. J. Jasmin. 1999. Expression of the utrophin gene during myogenic differentiation. Nucleic Acids Res. 27:3603-3609.

Guo, K., J. Wang, V. Andres, R. C. Smith, and K. Walsh. 1995. MyoD-induced expression of p21 inhibits cyclin-dependent kinase activity upon myocyte terminal differentiation. Mol.
Cell. Biol. 15:3823-3829.

Gurnett, C. A., D. M. Desruisseau, K. McCall, R. Choi, Z. I. Meyer, M. Talerico, S. E. Miller, J. S. Ju, A. Pestronk, A. M. Connolly, T. E. Druley, C. C. Weihl, and M. B. Dobbs. 2010. Myosin binding protein $\mathrm{C} 1$ : a novel gene for autosomal dominant distal arthrogryposis type 1. Hum. Mol. Genet. 19:1165-1173.

Halevy, O., B. G. Novitch, D. B. Spicer, S. X. Skapek, J. Rhee, G. J. Hannon, D. Beach, and A. B. Lassar. 1995. Correlation of terminal cell cycle arrest of skeletal muscle with induction of p21 by MyoD. Science 267:1018-1021.

Hollung, K., E. Veiseth, X. Jia, E. M. Faergestad, and K. I. Hildrum. 2007. Application of proteomics to understand the molecular mechanisms behind meat quality. Meat Sci. 77:97104.

Hwang, I. H., B. Y. Park, J. H. Kim, S. H. Cho, and J. M. Lee. 2005. Assessment of postmortem proteolysis by gel-based proteome analysis and its relationship to meat quality traits in pig longissimus. Meat Sci. 69:79-91.

Jia, X., K. Hollung, M. Therkildsen, K. I. Hildrum, and E. Bendixen. 2006. Proteome analysis of early post-mortem changes in two bovine muscle types: M. longissimus dorsi and M. semitendinosis. Proteomics 6:936-944.

Julve, J., J. C. Escola-Gil, A. Marzal-Casacuberta, J. OrdonezLlanos, F. Gonzalez-Sastre, and F. Blanco-Vaca. 2000. Increased production of very-low-density lipoproteins in transgenic mice overexpressing human apolipoprotein A-II and fed with a high-fat diet. Biochim. Biophys. Acta 1488:233-244.

Kanter, M. M., G. R. Lesmes, L. A. Kaminsky, J. La Ham-Saeger, and N. D. Nequin. 1988. Serum creatine kinase and lactate dehydrogenase changes following an eighty kilometer race. Relationship to lipid peroxidation. Eur. J. Appl. Physiol. Occup. Physiol. 57:60-63.

Kislinger, T., A. O. Gramolini, Y. Pan, K. Rahman, D. H. MacLennan, and A. Emili. 2005. Proteome dynamics during C2C12 myoblast differentiation. Mol. Cell. Proteomics 4:887901

Lametsch, R. and E. Bendixen. 2001. Proteome analysis applied to meat science: characterizing postmortem changes in porcine muscle. J. Agric. Food Chem. 49:4531-4537.

Lametsch, R., P. Roepstorff, and E. Bendixen. 2002. Identification of protein degradation during post-mortem storage of pig meat. J. Agric. Food Chem. 50:5508-5512.

Langen, R. C., J. L. Van Der Velden, A. M. Schols, M. C. Kelders, E. F. Wouters, and Y. M. Janssen-Heininger. 2004. Tumor necrosis factor-alpha inhibits myogenic differentiation through MyoD protein destabilization. FASEB J. 18:227-237.

Lee, E. J., A. Malik, S. Pokharel, S. Ahmad, B. A. Mir, K. H. Cho, J. Kim, J. C. Kong, D. M. Lee, K. Y. Chung, S. H. Kim, and I. Choi. 2014. Identification of genes differentially expressed in myogenin knock-down bovine muscle satellite cells during differentiation through RNA sequencing analysis. PLoS ONE 9:e92447.

Liu, Q. C., X. H. Zha, H. Faralli, H. Yin, C. Louis-Jeune, E. Perdiguero, E. Pranckeviciene, P. Munoz-Canoves, M. A. Rudnicki, M. Brand, C. Perez-Iratxeta, and F. J. Dilworth. 2012. Comparative expression profiling identifies differential roles for Myogenin and p38alpha MAPK signaling in myogenesis. J. Mol. Cell Biol. 4:386-397. 
Monin, G., E. Lambooy, and R. Klont. 1995. Influence of temperature variation on the metabolism of pig muscle in situ and after excision. Meat Sci. 40:149-158.

Montesano, A., L. Luzi, P. Senesi, N. Mazzocchi, and I. Terruzzi. 2013. Resveratrol promotes myogenesis and hypertrophy in murine myoblasts. J. Transl. Med. 11:310.

Morzel, M., C. Chambon, M. Hamelin, V. Sante-Lhoutellier, T. Sayd, and G. Monin. 2004. Proteome changes during pork meat ageing following use of two different pre-slaughter handling procedures. Meat Sci. 67:689-696.

Mullen, A. M., P. C. Stapleton, D. Corcoran, R. M. Hamill, and A. White. 2006. Understanding meat quality through the application of genomic and proteomic approaches. Meat Sci. 74:3-16.

Pette, D. 2002. The adaptive potential of skeletal muscle fibers. Can. J. Appl. Physiol. 27:423-448.

Picard, B., C. Berri, L. Lefaucheur, C. Molette, T. Sayd, and C. Terlouw. 2010. Skeletal muscle proteomics in livestock production. Brief. Funct. Genomics 9:259-278.

Qiu, H., X. Xu, B. Fan, M. F. Rothschild, Y. Martin, and B. Liu. 2010. Investigation of LDHA and COPB1 as candidate genes for muscle development in the MYOD1 region of pig chromosome 2. Mol. Biol. Rep. 37:629-636.

Sayd, T., M. Morzel, C. Chambon, M. Franck, P. Figwer, C. Larzul, P. Le Roy, G. Monin, P. Cherel, and E. Laville. 2006. Proteome analysis of the sarcoplasmic fraction of pig semimembranosus muscle: implications on meat color development. J. Agric. Food Chem. 54:2732-2737.
Spangenburg, E. E. and F. W. Booth. 2003. Molecular regulation of individual skeletal muscle fibre types. Acta Physiol. Scand. 178:413-424.

Stentz, R., R. J. Bongaerts, A. P. Gunning, M. Gasson, and C. Shearman. 2010. Controlled release of protein from viable Lactococcus lactis cells. Appl. Environ. Microbiol. 76:30263031 .

Wheeler, T. L., L. V. Cundiff, S. D. Shackelford, and M. Koohmaraie. 2005. Characterization of biological types of cattle (Cycle VII): Carcass, yield, and longissimus palatability traits. J. Anim. Sci. 83:196-207.

Wu, R. E., W. C. Huang, C. C. Liao, Y. K. Chang, N. W. Kan, and C. C. Huang. 2013. Resveratrol protects against physical fatigue and improves exercise performance in mice. Molecules 18:4689-4702.

Yan, J. X., R. Wait, T. Berkelman, R. A. Harry, J. A. Westbrook, C. H. Wheeler, and M. J. Dunn. 2000. A modified silver staining protocol for visualization of proteins compatible with matrixassisted laser desorption/ionization and electrospray ionization-mass spectrometry. Electrophoresis 21:3666-3672.

Zuo, X., L. Echan, P. Hembach, H. Y. Tang, K. D. Speicher, D. Santoli, and D. W. Speicher. 2001. Towards global analysis of mammalian proteomes using sample prefractionation prior to narrow $\mathrm{pH}$ range two-dimensional gels and using onedimensional gels for insoluble and large proteins. Electrophoresis 22:1603-1615. 